\title{
Popüler Kültürde Şiddet Olgusu üzerinden Recep İvedik 5 Filminin Analizi
}

\author{
Hakan Alp* \\ Fenerbahçe Üniversitesi \\ orcid.org/0000-0001-9696-8902
}

\author{
Erkan Turan \\ Fenerbahçe Üniversitesi \\ orcid.org/0000-0001-8387-240
}

\section{$\ddot{O} z$}

Türkiye'de son dönemde izlenme oranları gittikçe artan yerli dizi ve filmler, makalemizde üzerinde duracağımız kadına yönelik şiddet, baskı ve ayrımcılı̆̆ın en görünür olduğu yerlerdir. Çalışmada amacımız, eleştirel bir bakış açısıyla analiz edeceğimiz Recep İvedik karakterinin argo ve şiddetle sarmalanmış yaşam biçimini, arkadaşlı iliş̧ilerini, ayrımcı söylemin bu yeni nesil kahraman aracılığı ile nasıl toplumsallaştıılmaya çalışıldığııı açıklamak olacaktır. Makelemizde Recep İvedik 5 filminin ana karakterinin yaşam biçimi, fiziki şiddet eğilimleri, kadına yönelik kullandığ öğeleri ve bu şiddet eğiliminin sinema seyircisi olan kitleye verebileceği zararlar örneklerle irdelenecektir. Recep İvedik ve ardil sayılabilecek "Cumali Ceber", "Şefkat Yerimdar" tarzındaki filmler toplumdaki iktidar ilişkilerini popüler kültürle bağlantısını anlamak açısından önem taşımaktadır. Biz de çalışmamız kapsamında; popülerlik, medyada yer alma, gişe ve hasılat bakımından Türk Sinema tarihinin en fazla izlenen filmi Recep İvedik 5 filmini içerik analizi yöntemini kullanarak analiz edeceğiz. Popüler kültür ürünlerinde, özellikle dizi ve sinema sektöründe şiddet öğeleri, doğal, meşru ve dahası film kahramanları aracılığı ile sempatik hale getirilerek sunulmaktadır. Medya aracılığı ile şiddetin meşrulaştırması ve sempatik hale getirilmesi, bir arada yaşama kültürüne ciddi zararlar vermektedir. Özellikle izleyici kitlesinin çocuk ve gençlerin oluşturduğu Recep İvedik film serisinin, hemen hepsinde yer alan, argo, ayrımcl, ötekileştirici söylem ve kaba üslubun yaratacağ tehlikenin boyutları çok önemlidir. Makalemizin temel varsayımı budur. Popüler kültür ürünlerinin, şiddeti mizah öğeleriyle bezenmiş bir biçimde sunumunu yapması tehlikenin boyutların arttırmaktadır. Çünkü mizah öğeleri iletiyi daha da popülerleşmekte ulaştığı kitleye şiddet içeren iletinin doğal olduğu izlenimini aşılamaktadır. Recep İvedik film serisinin ulaştığı izleyici sayısı ve kitle profili düşünüldü̈̆̈̈̈nde, karakterin her davranışının özellikle çocuk ve gençler üzerinde ciddi tahribat yapabileceği ortadadır.

Anahtar Kelimeler: Cinsiyetçilik, Medya, Şiddet, Popüler, Ayrımcılık

\section{Analysis of Recep İvedik Film 5 in terms of Violence in Popular Culture}

\section{Abstract}

Turkish series and movies having high ratings are the places where violence against women, oppression and discrimination can be seen. The main purpose of this study is to analyze the sovereignty and violent life of Recep Ivedik character, his friendship relations, discriminatory discourse with a critical point of view and to explain the socialization of this character through this hero of new generation. In this study, the life style of the main character of Recep Ivedik 5, his physical violence notion, linguistic violence used towards women and the harmful impacts of this violence notion on the audiences will be examined. Films such as Recep İvedik and his successor "Cumali Ceber", Şefkat Yerimdar" are important for understanding the relation of power relations in the society with popular culture. Recep Ivedik 5, which is the most watched film in Turkish Cinema history, will be analyzed in terms of popularity, media coverage, box office and revenue by using content analysis in this study. In

\footnotetext{
*Yazışma adresi. Email: hakan.alp@fbu.edu.tr
} 
popular culture, especially in the TV series and cinema industry, violence is presented as natural, legitimate and, moreover, sympathetic through the movie heroes. The legitimization and sympathy of violence through the media has caused serious harm to the national culture. The trouble which slang, discriminatory, alienating rhetoric and vulgar style in all of the Recep İvedik film series, consisting of the audiences of children and young people is important. The presentation of popular culture products in the form of violence with elements of humor increases the extent of the harm. His humor elements make the message even more popular and he gives the impression that the message of violence that he wants to reach is natural. Considering the number of audiences reached by the Recep Ivedik film series, it is obvious that every behavior of the character can cause serious damage especially for children and young people.

Keywords: Sexism, Media, Violence, Popular, Discrimination

\section{Giriş}

İdeolojik bir mücadele alanı olarak tanımlanan medya, şiddetin ve cinsiyetçi toplumsal yaklaşımların yeniden üretildiği alanlardan birine dönüşmüş durumdadır. Sanatsal ve kültürel üretim biçim ve içerikleri, kadına yönelik şiddet, ayrımcılık ve baskıyı yeniden üretmektedir. Öte yandan egemen-geleneksel medya aracılığı ile bu söylem kendini meşrulaştırmaktadır.

Medya popüler kültürün dayattığı içeriklerin ideolojisini gizlerken, erkek egemen söylemi normalleştirmektedir. Söz konusu süreç toplumsal rızanın üretilmesiyle beraber kendine zemin bulabilmektedir. Sinema ve dizi sektörü, popüler olmaları, son yıllardaki izlenme oranlarının yüksek oluşu ve egemen ideolojinin ayrımcı söylemini öne çıkarması açısından önem taşımaktadır.

Şiddet eylemi sadece bir kişiye değil, etnik, dini, ulusal azınlıkları, farklı cinsel kimlikleri, yönelimlere de güç ve baskı uygulamayı kapsayabilir. Şiddet yoluyla, kendinden olmayan kişi veya grupları isteği dışında davranış biçimlerine yönlendirme yapılabilmektedir. Makale kapsamında analizini yaptığımız Recep İvedik 5 adlı filmde, özellikle Rus ve Yunan halklarına karşı sürekli bir biçimde hakaret, şiddet ve düşmanlık içeren söylem ve davranış biçimlerine sıklıkla rastlamaktayız.

Çalışmamız kapsamında irdelemeye çalışacağımız Recep İvedik film serisinin ana karakteri Recep karakteri; yukarıda sayılan ve "şiddet" olarak tanımlanan hareketlerin hemen hemen hepsini sıklıkla yapan bir karakterdir. Ayrıca filmde mizahi unsurlarla süslenen şiddet gösterimleri, şiddet kodlarına yeniden bir alan üretmektedir. Filmin ulaştığı izleyici sayısı düşünüldüğünde, toplumsal ilişkiler açısından bu öğrenilmiş kodların, genel ve meşrulaşmış davranış biçimleri olarak ortaya çıkması kaçınılmazdır. Film serisinin tüm bölümlerinde; haksızlıklara karşı kendi yöntemlerince karşı çıkan Recep karakterinin şiddet uygulamaları toplum tarafından meşru görülmektedir. Söz konusu durum; birey bazında herkesin kendi hukuk kurallarını uyguladığı, hiçbir norm ve kuralın tanınmadığı bir yaşamsal pratiğe neden olması açısından çok tehlikelidir. 


\section{Dil ve Şiddet}

\section{1. Şiddet}

Günümüze değin şiddetin birçok tanımı yapılmıştır. Şiddet (violence) kelimesi, güç anlamına gelen Latince "vio" kökünden türetilmiştir. Ayrıca şiddet kelimesi Dünya Sağlık Örgütü (WHO) tarafından, "fiziksel güç veya iktidarın kasıtlı bir tehdit veya gerçeklik biçiminde bir başkasına uygulanması sonucunda maruz kalan kişide yaralanma, ölüm ve psikolojik zarara yol açması ya da açma olasılığı bulunması" şeklinde tanımlanmaktadır (World Health Organization, 2002).

Erten ve Adalı'nın tanımlamasına göre şiddet, “insanlara şiddet kullanmak, kanuna uymamak, kişiye zarar vermek, hakaret etmek, onurunu kırmak, sükûnet ve huzura son vermek, birinin hakkını çiğnemek, hırpalamak, incitmek, canını acıtmak için zor kullanmak, yıkıcı aşırı davranışlarda bulunmak, aşırı derecede öfke ifade etmek şekillerinde kendini gösteren davranışlardır" (Erten, 1996).

Koç, şiddetin sadece fiziksel anlamda olmayabileceğini vurgulamaktadır. Bir kişinin herhangi ahlaki olmayan bir kelime kullanması, imalı bir şekilde bakması, başka bir kişinin duygularını incitmesi, onun bedenine veya eşyalarına zarar vermesi bir şiddet davranışıdır. Şiddet sadece silahla birini yaralama/öldürmeyi değil, aynı zamanda bir kişiye kızmayı ve bağırmayı da kapsar (Koç, 2011). Saygısızca kullanılan kelimeler, iletişim haline geçilen kişi veya grupları küçük düşürücü, aşağılayıcı söylemler, bakışlar, imalar da insan duygusunu incitebilen ve şiddet olarak tanımlayabileceğimiz davranış biçimleridir.

Michaud'a göre ise şiddet görüntülerinin doğal, estetik ve olduklarından daha zararsız olarak algılanması, şiddeti neredeyse etkisizmiş gibi gösterir. Böylece birey ve toplum için son derece zararlı olan gerçek şiddet ile görüntüsü arasında görünmeyen bir uçurum açılır. Tüketici izleyici, şiddetin ne denli tehlikeli bir olgu olduğunu ya artık göremez ya da görmezlikten gelir. Artık büyüsü bozulan şiddet, her türlü davaya hizmet eder.

Şiddet üzerine yapılan iletişim araştırmaları, şiddet gösterimlerinin şiddet kodlarını yeniden üretip kazandırdığını, gündelik hayatımızdaki gerilim anlarında bu öykülerden öğrendiğimiz davranış biçimlerinin devreye girerek kişisel eylemlere kılavuzluk ettiğini göstermiştir (Büker ve Kıran, 2004).

\subsection{Dilsel Şiddet}

Dilsel şiddetin amacı ise söylenecek sözle dinleyen üzerinde belirli bir etki yaratmaktır. Bu da toplumsal pratikte dilin rolünün ne kadar önemli ve vazgeçilmez olduğunu göstermektedir. Çok sayıda sözcük negatif değerleriyle sözlü saldırıların vazgeçilmez unsurlarıdır. Küfür sözcükleri daha çok tiksinti ve nefret uyandırır. Bu tür 
sözel saldırının hedefi karşısındaki birey veya grubu etkilemek, tiksindirmek, yıldırmak, korkutmak ve bu yolla egemenlik altına almaktır (Karabağ, 2010).

Dil sadece şiddeti temsil etmez veya etki yaratmakla kalmaz aksine söylemlerimizi kimi zaman gerçekleştirdiği bağlam içerisinde bir tür şiddet uygulaması olabilir. Edimsel bir bilgilendirme içeriğinde dil ve şiddet ilişkisinin analizi söz konusudur. Buradaki önemli sorun; dildeki şiddet ve güç unsurlarının ne şekilde açıklanabileceğidir. Normalde bir kimsenin başkasına veya bir grubun başka bir gruba fiziki-sözlü saldırısı şiddet uygulamasıdır. Yani şiddetin adresi bir kişi veya gruptur (Karabağ, 2010). Söz konusu dilsel şiddetin, Recep İvedik filmlerinin hemen hepsinde toplumsal birçok gruba karşı yapıldığına defalarca tanık olmaktayız. Seri filmlerin konusuna göre dilsel şiddet; kimi zaman kadına yönelik olabilirken, kimi zaman da insanların fiziki özelliklerine yönelik olabilmektedir. Gündelik yaşamda, çekirdek aileden başlayan ayrımcı, dışlayıcı, şiddet içeren söylemler, okullarda, iş yaşamında ya da makale kapsamında analizini yapacağımız kültür ürünlerinde olduğu gibi, farklı biçimlerde de olsa karşımıza çıkmaktadır. Söz konusu söylemin sanat ve kültür yapıtlarında yeniden üretilmesi; dilsel şiddetin normalleştirilmesi ve bu söyleme meşruiyet sağlaması açısından değerlendirildiğinde, üzerinde ciddiyetle durulması gereken bir olgudur.

Dilsel şiddet söylemi kimi zaman imajda kimi zaman da bir beden hareketinde de ortaya çıabilmektedir. Karabağ'a göre ideal olanın iletişimin şiddet ve nefret söyleminden arındırılması ve etkileşimin rasyonel-eşit koşullarda sağlanmasıdır. Bu arınma sürecinin toplumsal gruplar arasındaki barışı yeniden tesis edebileceği çok açıktır.

\section{Yozlaşan Medya Kültürü}

Horkheimer Akıl Tutulması adlı eserinde endüstrileşen kültürün sanal bir eğlenceye dönüştüğünü belirtir. "Tıpkı annesinin sözlerini tekrarlayan bir çocuk ya da yetişkinlerin tavırlarını benimseyen bir genç gibi, sınaî kültür denen o dev hoparlör de, ticarileşmiş eğlence- dinlencelerin ve her gün birbirine daha çok benzeyen reklamların sağır edici gürültüsünde, gerçekliğin yüzeyini sonsuza kadar tekrarlayıp durmaktadır. Eğlence sanayinin bütün ustalığı, o bayatlamış yaşam sahnelerini tekrar piyasaya sürmekten ibarettir; ama bunda yine de başarılı olduğu görülmektedir. Çünkü yeniden üretimin teknik ustalığı ideolojik içeriğin yanlışlığını örtmektedir. Aynı zaman da bu içeriğin oldukça keyfi bir biçimde içine sokuluşunu örtmektedir" (Horkheimer, 1998).

Recep İvedik film serilerinin birbirlerine benzeyen hikâye kurguları ve şiddetle beslenen eğlence temaları, sözde gerçekliğin yeniden üretilmesine neden olmaktadır. Hikâye kurgusu gereği bir yandan mağduriyete karşı bir kahraman olarak lanse edilen Recep karakteri, birbirine benzeyen mizah anlayışı temalarını tekrarlayıp durmaktadır. Recep İvedik 5 filminin, Türkiye'deki toplam 2 bin 500 sinema salonunun bin 529'unde vizyona girmesi "sınai kültür denen o dev hoparlörün" gücünü göstermesi açısından çok 
önemli bir veridir. Bu durum bir yandan söz konusu toplumsal pratiğin bir seçim mi yoksa bir zorunluluk mu olduğu tartışmasını beraberinde getirmektedir.

Popüler kültür ürünlerinin bombardımanına maruz kalmanın yanında şöyle bir durum söz konusudur; gündelik hayatın rutin işleyişi içerisinde yorulan, sıkılan insanların ciddi ya da nitelikli ürünlerden çok eğlendirici ürünlerle, "vakit geçirtmeyi" seçmelerine "realiteden kaçış eğilimi” denmektedir (Oskay, 2016). Oskay'a göre realiten kaçış; bireyin kendi yaşamındaki sorunların ana nedenlerini ve çözüm pratiklerini analiz etmesini gittikçe güçleştirmektedir. Ekonomik sorunlar, işsizlik, çocuk işçi sorunu, kadına yönelik şiddet ve cinayetleri düşünmek ve bu sorunlara cevap aramak yerine, popüler kültür ürünlerindeki sanal gerçeklik ve kaçış olanağı insanlara daha çekici gelmektedir.

Popüler kültürü, iktidarla toplum arasındaki bir çekişme alanı olarak tanımlayan Hall şöyle devam eder; "Popüler kültür daima iktidar ilişkilerinin bir parçasıdır; içinde iktidarın elinde bulundurduğu güce karşı direnmenin ve bu güçten sıyrılmanın izlerini taşır. Kısmen hegemonyanın yükseldiği ve aynı anda güvenlik altına alındı̆̆ı yerdir" (Hall, 1994). Recep İvedik ve benzeri formattaki filmlerin alt mesajları; aslında toplumun değer yargılarını, hayata bakış açılarını, geleceğe dair umutlarını ve çözüm noktalarını anlamamız adına önemli bir veri oluşturmaktadır.

\section{Medya ve Şiddet Kültürü}

Medyada yer alan şiddet betimlemelerinin sıklığı, onları bireyin günlük yaşamının bir parçası haline getirmiştir. Kitle iletişim araçlarının hemen hemen hepsinde sıklıkla şiddet içeren görüntülere rastlamaktayız.

Medyada şiddet üzerine nicelik araştırması yapan kimi çalışmalarda, bir çocuğun 18 yaşına gelene kadar 200 bin simülasyon şiddet hareketi ve 16 bin öldürme sahnesi gördüğ̈̈nü belirtmektedir (Trend, 2008).

Türkiye'yi düşündüğümüzde eğitim düzeyinin düşük olması ve şiddet konusundaki bilinçlenmenin yeteri kadar gelişmemiş olması, hem toplumda hem de medyada şiddetin ve nefret söyleminin kimi biçimlerinin sıradan ve kabul edilebilir olarak algılanmasına neden olmaktadır. İnsan hakları, farklılıklara ve öteki diye adlandırabileceğimiz toplumsal sınıf ve gruplara yönelik saygı ve bir arada yaşama kültürü henüz ideal oranda varlık kazanamamıştır (Cheviron, 2014).

Özellikle cinsiyetler arası ilişkilerde toplumda hala eril bir dilin kullanıldığını; kadına yönelik aşağılayıcı, küçük düşürücü ve ayrımcı söylemin popüler kültür ürünlerinde sıkça kullanıldığına tanık olmaktayız. Söz konusu söylem, toplumda kadını sadece ev işleri yapan; evin, çocukların bakımını, temizliğini, mutfak işlerini üstlenen bir konumda olmasını olağanlaştıran bir süreci tetiklemektedir. 
Aile içinde başlayan, daha sonra yukarıdaki örnekte gördüğümüz biçimlerce eğitim sistemi aracılığıyla yeniden üretilen söylemler, popüler kültür ürünleri tarafından da topluma sunulunca siradan ve kabul edilebilir bir hale gelmektedir.

Medya ve dizi-film sektörü; öteki olarak adlandırabileceğimiz tüm gruplara karşı şiddeti meşrulaştırmaktadır. Özellikle milyonlarca insan tarafından (ki bu sayının büyük bir bölümünü çocukların ve gençlerin oluşturduğunu söyleyebiliriz) izlenen popüler kültür ürünleri toplumsal yapıya onarılmaz zararlar vermektedir. Bu zararları Cheviron şöyle siralamaktadır (Cheviron, 2014: 66):

1. Medyadaki şiddet içeren görüntüler saldırgan davranışların oranını arttırmaktadır.

2. Şiddetin günlük ve sıradan bir olgu olarak algılanmasına neden olmaktadır. Bunun nedenleri ise şunlardır: Medyadaki şiddet yüzünden;

a. Günlük yaşamın en sıradan anlarında sürekli şiddet görüntüleriyle karşı karşıya kalan insanlar şiddete karşı duyarsızlaşmaktadır.

b. Güce dayalı ilişkiler idealleştirilmektedir.

c. Anlatıların içeriğgi fakirleşmektedir ve anlamsızlaşmaktadır.

Trend, medyanın en büyük şiddet izleyicilerinin ergen erkek çocukları olduğunu söylemektedir. "Genç erkekler, şiddet içerikli medyayı izlemeyi cinsiyet tanımlamanın önemli bir parçası olarak görerek sosyalleşirler.(Trend, 2008) Konu özellikle Recep İvedik karakterinde olduğu gibi "taklit" olduğunda, şiddet imgelerinin çocukları daha çok çektiği çok açıktır.

Televizyonda şiddet unsuru içeren filmler, diziler, çizgi filmler gençlerin suç olaylarına karışmasını güçlendirebilmektedir. Bu şiddet unsurları TV'deki karakterlerin davranışlarını taklit etme eğiliminde olan, kimliğini oluşturma sürecindeki gençlerde suç davranışına yol açabilmektedir"' (Sadi, 2007).

Popüler Kültürün temel özelliklerinden biri, görüntüye dayanan, özden yoksun güncel söylemlerden kaynaklanan, sı̆̆ ve yüzeysel bilgiyi içermesidir. Kitle iletişim araçları, birey ve toplumu yakından ilgilendiren sosyal, ekonomik, siyasal ve ekonomik konuları arka plana iterek, yozlaşmış olan popüler kültür ürünlerine öncelik vermektedir (Köknal, 2013: 150). Dolayısıyla medyatik söylem ve popüler kültür ürünleri, bireyi, olguların neden sonuç ilişkilerini görmekten alıkoymaktadır. Söz konusu süreç bireyin kendisine ve yaşadığı topluma yabancılaşma sürecini de tetiklemektedir.

Althuser, devletin (ya da hâkim ideolojinin) kendi kurallarını uygulamak ve düzenini tesis etmek için baskı ve ideolojik aygıtları kullandığını belirtmektedir. Baskı aygitları ve ideolojik aygıtlar birbirlerinden kavramsal olarak farklı anlamlar taşımaktadır. Baskı aygıtları genel olarak, hükümet, ordu, polis, mahkemeler, cezaevleridir. İdeolojik aygıtlar ise dinsel, eğitsel, hukuki, siyasal, kültürel, dilsel, haberleşme kurumlarını içerir 
(Althuser, 2003). Kültürel kurumların en popüler olanlarından film ve dizi sektörü ulaştı̆̆1 kitle sayısı ve etki alanı açısından düşünüldügünde ciddi bir konuma sahiptir. Şiddetin meşrulaştırılması ile başlayan konumlanma; şiddetin toplum tarafından içselleştirmesine kadar uzanan bir süreci de içine almaktadır. Şiddet söyleminin yeniden üretilmesi ve yinelenmesinin etkisi, toplumsal tahribatı arttırmaktadır.

Recep İvedik film serisi, tam da bu noktada toplumsal yozlaşmaya yaptığ etki açısından ciddiyetle üzerinde durulması gereken bir üründür. Recep karakteri; şiddet içeren davranışları, saygısız üslubu, hiçbir değer yargısı olmayan kişiliği ve kabalığı ile özellikle çocuk yaşlardaki izleyici kitle açısından örnek alınmaktadır. Bu örnek alınma hali, kimi zaman karakterin yaptığı kaba hareketler ya da küfürleri sonrası gülüşünün, taklit edilmesine kadar varabilmektedir. Kimi zaman da Recep karakterinin saygısız ve kaba bedensel hareketleri genç kuşaklar arasında fenomen hale gelebilmektedir.

\section{Recep İvedik 5 Filminin“Şiddet Kavramı” Üzerinden Analizi}

Analiz kapsamında amaç; Recep İvedik karakterinin argo ve şiddetle sarmalanmış yaşam biçimini, arkadaşlık ilişkilerini, ayrımcı söylemin bu yeni nesil kahraman aracılığı ile nasıl toplumsallaştırılmaya çalışıldığını açıklamak olacaktır. Analizimizde Recep İvedik 5 filminin ana karakterinin yaşam biçimi, fiziki şiddet eğilimleri, kadına yönelik kullandığ1 dilsel şiddet öğeleri ve bu şiddet eğiliminin sinema seyircisi olan kitleye verebileceği zararlar örneklerle irdelenecektir. Makalemiz, Recep İvedik film serisinin son filmi olan Recep İvedik 5 filminin incelenmesi ile sınırlıdır. Recep İvedik 5 filmini içerik analizi yöntemini kullanarak eleştirel bir bakış açısı ile analiz edeceğiz.

Recep İvedik film serileri ilk vizyona çıktığı tarihten bugüne kadar toplam 26.767.069 izleyici tarafından izlenmiştir. Film serisi toplamda 64.723.892 TL hasılat elde etmiştir.

Makale kapsamında da analizini yapacağımı Recep İvedik 5 filmi, vizyona girmeden önce fragmanı toplamda 28 milyon kişi tarafından izlenmiştir. Film tek başına 85 milyon liralık hasılata ulaşarak, 2017 yılının toplam hasılatının yüzde 22'sini elde etmiştir.

Tablo 1. Recep İvedik Film Serisinin Toplam İzleyici Sayısı ve Hasılatı

\begin{tabular}{|c|c|c|}
\hline Film Adı & İzleyici Sayısı & Toplam Hasılat \\
\hline Recep İvedik 5 & 7.437 .050 & $85.986 .157 €$ \\
\hline Recep İvedik 4 & 7.369 .098 & $72.103 .216 €$ \\
\hline Recep İvedik 3 & 3.326 .084 & $28.712 .099 €$ \\
\hline Recep İvedik 2 & 4.333 .144 & $33.493 .326 €$ \\
\hline Recep İvedik & 4.301 .693 & $30.172 .530 €$ \\
\hline Toplam & 26.767 .069 & $250.467 .328 €$ \\
\hline
\end{tabular}

Kaynak: Https://boxofficeturkiye.com/tumzaman/?tm=1989 
"Sinemia adlı internet portalına ait Sinemia Premium üyeleri ve ayda 22 milyon tekil kişiye ulaşan SinemiaSocial takipçilerinin tercihlerine göre yapılan araştırma, filmin ana izleyici kitlesinin Y jenerasyondan erkekler olduğunu ortaya koydu. Şubat - Mart döneminde sinemaya giden her 2 erkekten 1'i Recep İvedik 5'i izledi. Anadolu'da her 4 sinemaseverden 3'ü bu filmi tercih etti.

Rakamlara göre, Recep İvedik 5; yüzde 38'lik oranla en çok 26-35 yaş grubundaki insanlar tarafından izlendi. Bu grubu yüzde 31 ile 21-26 yaş arası gençler takip etmiştir. Sinemaya giden her 3 kadından 1'i Recep İvedik 5'i tercih ederken, erkek izleyicilerin ise yarısının filmi izlediği görülüyor. Tüm bu istatistikler, filmin hitap ettiği ana kitlenin Y jenerasyonundan erkekler olduğunu söylemektedir."1

\subsection{Filmin Konusu ve Analizi}

Recep İvedik (Şahan Gökbakar) mahallesinde yaşayan bir şoför tanıdığının vefatı sonrası taziye evine gittiğinde, adamın aldığı, ancak ömrü yetmediği için tamamlayamadığı son işi yerine getirmek için gönüllü olur. Bu da Avrasya Gençlik Oyunları'na katılacak milli takım kafilesini Makedonya'ya götürmektir. Yolda Recep'in yaptığı kuru fasulye, sporcuların zehirlenmesine neden olunca kafile başkanı, takımı oyunlardan çekmekten başka bir çare düşünemez. Ancak o noktada Recep kafile başkanlığını ele alır ve rahatsızlanan sporcuların yerine kamyoncu arkadaşlarını çağırır. ${ }^{2}$

Film sırasında Recep karakterinin davranış biçimini analiz ettiğimizde, ayrımcı söylemlere, hakaretlere ve şiddet öğelerine rastlamaktayız. Filmin henüz başlangıç sahnelerinde aynı mahallede yaşadığı insanlara, şiddet içerikli şakalar yapması, turnuvaya otobüsle giderken yol boyunca yaptığ 1 anlamsız hareketler, hastane ve otel sahnelerindeki küfür ve hakaret dolu cümleleri, Rus rakibine ikram ettiği lokumun içine doping koyması, yarış sırasında rakiplerine hakaret ederek dikkatlerini dağıtmak vb. hareketlerle dolu olan filmin; şiddet ve hakaret içeren sahneleri aşağıda sıralı halde yer almaktadır.

1https://indigodergisi.com/2017/04/recep-ivedik-rekora-tasiyanlar/ 2https://www.sinemalar.com/film/225696/recep-ivedik-5 
Tablo 2. Recep İvedik 5 Filminden “Kanuna Uymamak ve İnsanlara Şiddet Kullanma” Kategorisinden örnekler

\begin{tabular}{|c|c|}
\hline Şiddet Kategorisi & Örnek \\
\hline Kanuna Uymamak & $\begin{array}{l}\text { *Spor kafilesini Üsküp'e yarışmalara götürürken seyir } \\
\text { halinde şoför değişikliği yapmak }\end{array}$ \\
\hline \multirow{7}{*}{ İnsanlara Şiddet Kullanmak } & *Bakkalın kafasına kova geçirme \\
\hline & $\begin{array}{l}\text { *Mahalle kahvesinde uyuklayan adamın ayağını dibinde } \\
\text { çatapat patlatmak }\end{array}$ \\
\hline & $\begin{array}{l}\text { *Kahvede oturan arkadaşının yüzüne su fırlatmak/kafasına } \\
\text { jelatin geçirmek/kafasında yumurta kırmak/un atmak }\end{array}$ \\
\hline & $\begin{array}{l}\text { "Arkadaşının ensesine vurup, "lan sen ne kadar } \\
\text { yavşakmışsın" diyerek hakaret etmesi }\end{array}$ \\
\hline & $\begin{array}{l}\text { *Kafile başkanına telefonunu kapatmasını söyleyip tokat } \\
\text { atarak bayıltması }\end{array}$ \\
\hline & *Yardımcisını tekmeleme \\
\hline & *Rakip sporcuyu otel odasından havuza atmak \\
\hline
\end{tabular}

Tablo 3. Recep İvedik 5 Filminden “Kişiye Zarar Vermek” Kategorisinden örnekler

\begin{tabular}{|c|c|}
\hline Şiddet Kategorisi & Örnek \\
\hline \multirow{11}{*}{ Kişiye Zarar Vermek } & *Arabayla birini ezme şakası \\
\hline & *Merdivenle çalışan işçinin altından merdiveni çekmek \\
\hline & ${ }^{*}$ Gazete okuya adamın elindeki gazeteyi yakmak \\
\hline & *Bakkalın kafasına kova geçirme \\
\hline & $\begin{array}{l}\text { *Mahalle kahvesinde uyuklayan adamın ayağını dibinde } \\
\text { çatapat patlatmak }\end{array}$ \\
\hline & $\begin{array}{l}\text { *Kahvede oturan arkadaşının yüzüne su fırlatmak/kafasına } \\
\text { jelatin geçirmek/kafasında yumurta kırmak/un atmak }\end{array}$ \\
\hline & $\begin{array}{l}\text { *Cenaze namazında öne geçmek amacıyla yanında duran } \\
\text { adamı itmek }\end{array}$ \\
\hline & $\begin{array}{l}\text { *Otobüste muavinlik yaparken bilerek sporcuların üzerine } \\
\text { kaynar su dökmek }\end{array}$ \\
\hline & $\begin{array}{l}\text { *Kafile başkanına telefonunu kapatmasını söyleyip tokat atarak } \\
\text { bayıltması }\end{array}$ \\
\hline & *Yardımcisını tekmeleme \\
\hline & *Rakip sporcuyu otel odasından havuza atmak \\
\hline
\end{tabular}


Tablo 4. Recep İvedik 5 Filminden “Hakaret Etmek" Kategorisinden örnekler

\begin{tabular}{|c|c|}
\hline Şiddet Kategorisi & Örnek \\
\hline \multirow{14}{*}{ Hakaret Etmek } & $\begin{array}{l}\text { *Cenaze namazında öne geçmek amacıyla yanında duran } \\
\text { adama hakaret etmek }\end{array}$ \\
\hline & $\begin{array}{l}\text { *Sporcu kafilesi başkanina "Halk ne derse o olur, bok yemek } \\
\text { düşer sana" şeklinde hakaret etmek }\end{array}$ \\
\hline & $\begin{array}{l}\text { "Kafiledeki sporcu kadına, "sen sporcusun, biz neyiz bok } \\
\text { muyuz" diye hakaret etmesi }\end{array}$ \\
\hline & $\begin{array}{l}\text { *Hastanede doktora, "mademki kendi kendine iyileşecek } \\
\text { bunlar, sen ne bokuma duruyon/ seni ne bokuma profesör } \\
\text { yaptılar/ gerizekalı, kafanda saç kalmamış/dingil/ }\end{array}$ \\
\hline & $\begin{array}{l}\text { *Arkadaşının ensesine vurup, "lan sen ne kadar } \\
\text { yavşakmışsın" diyerek hakaret etmesi }\end{array}$ \\
\hline & $\begin{array}{l}\text { *Arkadaşına "sen ne büyük bir götlekmişsin" diyerek hakaret } \\
\text { etmesi }\end{array}$ \\
\hline & $\begin{array}{l}\text { *Otel odasında arkadaşının kolunu gösterip, "insan kolu mu } \\
\text { bu, hayvan kolu mu; resmen hayvan kolu" demesi }\end{array}$ \\
\hline & $\begin{array}{l}\text { *Telefonda yarışa çağırdığı arkadaşlarına; "gölge olur çınar } \\
\text { altı, girsin sana F16/ O laflar boy boy, sana kayar Recep } \\
\text { Kovboy/ O pencere bu pencere, sana girsin düdüklü tencere }\end{array}$ \\
\hline & $\begin{array}{l}\text { *Tüm ülke rakiplerin olduğu toplantıda, " hepinize koyacağız, } \\
\text { geçeceğiz" diyerek hakaret etmesi }\end{array}$ \\
\hline & $\begin{array}{l}\text { "Yemek yarışmasında Yunan rakiplerine, "bakalım bu } \\
\text { dingiller ne hazırlamış" diyerek hakaret etmesi }\end{array}$ \\
\hline & *Tüm rakip oyunculara dönüp, “koydum mu size” demesi \\
\hline & $\begin{array}{l}\text { * Kendi takım arkadaşına, "nehir kenarında balık bekleyen boz } \\
\text { ayı gibi" şeklinde hakaret etmesi }\end{array}$ \\
\hline & $\begin{array}{l}\text { *Hakeme rüşvet teklif etmesi ve hakemin kabul etmemesi } \\
\text { sonrası, " puu! allah belanı versin" demesi }\end{array}$ \\
\hline & $\begin{array}{l}\text { *Rakip sporcuya, "ne oldu Nikolay, sana koymak ne kolay" } \\
\text { demesi }\end{array}$ \\
\hline
\end{tabular}


Tablo 5. Recep İvedik 5 Filminden “Onurunu Kırmak” Kategorisinden örnekler

\begin{tabular}{|c|c|}
\hline Şiddet Kategorisi & Örnek \\
\hline \multirow{17}{*}{ Onurunu Kirmak } & $\begin{array}{l}\text { Cenaze evinde, helva yerken ağzından garip sesler çıarmak } \\
\text { ve tabağa tükürmek }\end{array}$ \\
\hline & *Eşi vefat eden kadına, eşiyle ilgili kötü sözler söylemek \\
\hline & $\begin{array}{l}\text { *Sporcu kafilesi başkanina "Halk ne derse o olur, bok yemek } \\
\text { düşer sana" şeklinde hakaret etmek }\end{array}$ \\
\hline & $\begin{array}{l}\text { *Kafiledeki sporcu kadına, "sen sporcusun, biz neyiz bok } \\
\text { muyuz" diye hakaret etmesi }\end{array}$ \\
\hline & $\begin{array}{l}\text { *Hastanede doktora, "mademki kendi kendine iyileşecek } \\
\text { bunlar, sen ne bokuma duruyon/ seni ne bokuma profesör } \\
\text { yaptılar/ gerizekalı, kafanda saç kalmamış/dingil/ }\end{array}$ \\
\hline & $\begin{array}{l}\text { *Arkadaşının ensesine vurup, "lan sen nekadar yavşakmışsın" } \\
\text { diyerek hakaret etmesi }\end{array}$ \\
\hline & $\begin{array}{l}\text { *Arkadaşına "sen ne büyük bir götlekmişsin" diyerek hakaret } \\
\text { etmesi }\end{array}$ \\
\hline & $\begin{array}{l}\text { *Otel odasında arkadaşının kolunu gösterip, "insan kolu mu } \\
\text { bu, hayvan kolu mu; resmen hayvan kolu" demesi }\end{array}$ \\
\hline & $\begin{array}{l}\text { *Telefonda yarışa ağırdığı arkadaşlarına; “ gölge olur çınar } \\
\text { altı, girsin sana F16/ O laflar boy boy, sana kayar Recep } \\
\text { Kovboy/ O pencere bu pencere, sana girsin düdüklü tencere }\end{array}$ \\
\hline & $\begin{array}{l}\text { "Yemek yarışmasında Yunan rakiplerine, "bakalım bu } \\
\text { dingiller ne hazırlamış" diyerek hakaret etmesi }\end{array}$ \\
\hline & $\begin{array}{l}\text { *Tüm ülke rakiplerin olduğu toplantıda, "hepinize koyacağız, } \\
\text { geçeceğiz" diyerek hakaret etmesi }\end{array}$ \\
\hline & *Çinli rakiplere, "Allah bunların belasını vermiş" demesi \\
\hline & *Tüm rakip oyunculara dönüp, "koydum mu size"demesi \\
\hline & $\begin{array}{l}\text { * Kendi takım arkadaşına, "nehir kenarında balık bekleyen boz } \\
\text { ayı gibi" şeklinde hakaret etmesi }\end{array}$ \\
\hline & *Rakip sporcuya, "herkesin tuttuğu kendine" demesi \\
\hline & $\begin{array}{l}\text { "Hakeme rüşvet teklif etmesi ve hakemin kabul etmemesi } \\
\text { sonrası, " pu! allah belanı versin" demesi }\end{array}$ \\
\hline & $\begin{array}{l}\text { *Rakip sporcuya, "ne oldu Nikolay, sana koymak ne kolay" } \\
\text { demesi }\end{array}$ \\
\hline
\end{tabular}


Tablo 6. Recep İvedik 5 Filminden Genel Şiddet Örnekleri

\begin{tabular}{|c|c|}
\hline Şiddet Kategorisi & Örnek \\
\hline $\begin{array}{l}\text { Sükûnet ve Huzura Son } \\
\text { Vermek }\end{array}$ & *Cenaze namazında yanında duran adama hakaret etmek \\
\hline $\begin{array}{l}\text { Birinin Hakkını } \\
\text { Çiğnemek }\end{array}$ & ${ }^{*}$ Cenaze namazında yanında duran adamı itmek \\
\hline \multirow{7}{*}{$\begin{array}{c}\text { Hırpalamak, İncitmek, } \\
\text { Canını Acıtmak İçin Zor } \\
\text { Kullanmak }\end{array}$} & *Arabayla birini ezme şakası \\
\hline & ${ }^{*}$ Merdivenle çalışan işçinin altından merdiveni çekmek \\
\hline & ${ }^{*}$ Gazete okuya adamın elindeki gazeteyi yakmak \\
\hline & *Bakkalın kafasına kova geçirme \\
\hline & $\begin{array}{l}\text { *Mahalle kahvesinde uyuklayan adamın ayağını dibinde } \\
\text { çatapat patlatmak }\end{array}$ \\
\hline & $\begin{array}{l}\text { *Kahvede oturan arkadaşının yüzüne su fırlatmak/kafasına } \\
\text { jelatin geçirmek/kafasıda yumurta kırmak }\end{array}$ \\
\hline & ${ }^{*}$ Rakip sporcuyu otel odasından havuza atmak \\
\hline \multirow{3}{*}{$\begin{array}{c}\text { Yıkıcı Aşırı } \\
\text { Davranışlarda } \\
\text { Bulunmak }\end{array}$} & *Çinli rakiplere, "Allah bunların belasını vermiş" demesi \\
\hline & "Hakeme, "Erkek adam silah çekiyorsa sıkacak" demesi \\
\hline & ${ }^{*}$ Rakip sporcuyu otel odasından havuza atmak \\
\hline \multirow{2}{*}{$\begin{array}{l}\text { Aşırı Derecede Öfke } \\
\text { İfade Etmek }\end{array}$} & $\begin{array}{l}\text { *Sporcu kafilesi başkanına "Halk ne derse o olur, bok } \\
\text { yemek düşer sana" şeklinde hakaret etmek }\end{array}$ \\
\hline & ${ }^{*}$ Rakip sporcuyu otel odasından havuza atmak \\
\hline
\end{tabular}

\section{Sonuç}

Kitle iletişim araçlarının, özellikle televizyon ve sinemanın içerik üretiminde kullandığ1 dil ve söylem biçimleri şiddeti meşrulaştırmaktadır. Toplum psikolojisi açısından değerlendirildiğine şiddetin normalleştirilmesi, şiddete maruz kalan insanlarda susma ve boyun eğme eğilimini ortaya çıkarmaktadır.

Şiddet ve ayrımcı söylem içeren dizi ve filmlerin talep gördüğü bir toplumsal yapı, belli bir süre sonra şiddeti meşrulaştırmakta ve şiddetin uygulamalarına karşı duyarsızlaşmaktadır. Recep İvedik ve benzer içerik-üsluba sahip filmler şiddet barındıran içeriklerine rağmen eğlence unsuru olarak sunulabilmektedir.

Eğlence olarak tasarlanan filmlerde, karşısındaki bireye şiddet uygulamanın meşrulaştırıldığı, kadına yönelik aşağılayıcı söylemlerin yeniden üretildiği, şiddetin özendirildiği ve cinsiyet ayrımcılığının en üst seviyede olduğu sahneler ne yazık ki en popüler sahneler olabilmekte ve sosyal medya aracılı̆̆ıla en fazla paylaşılan sahneler olmaktadır. Bu durum söylemin ve şiddet imgelerinin yeniden üretilmesine neden olmaktadir. 
Özellikler çocuk ve genç kitlelerde Recep İvedik karakterinin davranış biçiminin, farkında olmadan olsa da zihinlere yerleştirdiği şiddet davranışını, günlük yaşamlarında uygulamaları da kaçınılmaz olmaktadır.

\section{Kaynakça \\ Kitaplar}

Althuser, L. (2003). İdeoloji ve Devletin İdeolojik Aygıtları. İstanbul: İthaki Yayınları.

Büker, S. ve Kıran, A. (2004). Reklamlarda Kadına Yönelik Şiddet, İstanbul: Alan Yayıncılık.

Cheviron, N. (2014). Televizyon ve İçimizdeki Şiddet, İstanbul: Ekslibris Yayınları.

Hall, S. (1994). İdeoloji Ve İletişim Kuramı, Medya, İktidar, İdeoloji. Ankara: Ark Yayınları.

Hoorkheimer, M, (1998). Akıl Tutulması, İstanbul: Metis Yayınları.

Karabağ, İ. (2010). Dil ve Şiddet. İstanbul: İkaros Yayınları.

Koç, B. (2011). Okullarda Şiddet, İstanbul: E Yazı Yayınları.

Köknel, Ö. (2013). Şiddet Dili, İstanbul: Remzi Kitabevi.

Oskay; Ü. (2016). İletişim $A B C^{\prime}$ si. İstanbul: İnkılap Yayınları.

Trend, D. (2008). Medyada Şiddet Efsanesi. İstanbul: Yapı Kredi Yayınları.

\section{Diğer Kaynaklar}

Erten, Y. ve Ardalı, C. (1996). Saldirganlik, Şiddet ve Terörün Psikosoyal Yapıları. Cogito (Şiddet Özel Sayısı) Sayı 6-7 İstanbul: Yapı Kredi Yayınları.

İndigo Editör (2017). Recep İvedik'i rekora taşıyanlar kimler? 14 Haziran 2018 tarihinde https://indigodergisi.com/2017/04/recep-ivedik-rekora-tasiyanlar/ adresinden erişildi.

Sadi, E. (2007). Ergenlerin Kimlik Oluşturma Sürecine Televizyon Programlarmin Etkileri. Yayımlanmamış Yüksek Lisans Tezi. Ankara Gazi Üniversitesi Eğitim Bilimleri Enstitüsü.

World Health Organization (2002). World Report on Violence and Health Geneva: WHO. 14 Haziran $2018 \quad$ tarihinde http://www5.who.int/violence_injury_prevention/download.cfm?id=0000000582 adresinden erişildi. 